\title{
SURINAME ONDER ENGELSCH BEWIND
}

DOOR

W. R. MENKMAN

Bijdrage tot de kennis van het Engelsche tusschenbestuur van Suriname, I804-I8I6. Academisch proefschrift van J. F. E. Einaar, Leiden 1934.

Sedert in Suriname een op Nederlandsche leest geschoeide onderwijsvoorziening tot stand gekomen is, hebben vele zonen des lands in Nederland een wetenschappelijke opleiding genoten; vergis ik mij niet evenwel, dan is de Heer Einaar de eerste Surinamer die aan een Nederlandsche universiteit den graad van doctor in letteren en wijsbegeerte verwierf. Een promotie, zou ik zeggen, van beteekenis voor Suriname, wegens het groote belang dat de aldaar geborenen de aangelegenheden van het eigen land met breeden blik leeren beoordeelen. „Aan allen, die stre,,ven naar den socialen en economischen vooruitgang van Surina„me” droeg de Heer Einaar zijn dissertatie op.

De titel van Einaar's werk wekt verwachtingen op, waaraan moeilijk te voldoen was. Viel er aan onze kennis van het Britsche bewind over Suriname in de jaren 1804-1816 inderdaad nog wel veel toe te voegen?

Er bestaan nu eenmaal van die onderwerpen, waarover op een bepaald oogenblik niets van beteekenis meer te zeggen is. S. P. L'Honoré Naber heeft eens geschreven, dat met hetgeen Barlaeus en Netscher ons van de geschiedenis van Nederlandsch Brazilië medegedeeld hebben, de stof geheel verwerkt was, zoodat er aan nieuwe publicaties geen behoefte bestond. Zoo heeft, naar mijn bescheiden meening, met betrekking tot het door den Heer Einaar behandelde onderwerp, Wolbers de beschikbare bronnen vrijwel uitgeput, zoodat er niet veel nieuw licht meer te ontsteken viel

E. heeft dan ook van Wolbers' Geschiedenis van Suriname een 
ruim gebruik gemaakt, maar waarom hij in zijn litteratuurlijstje ook opnam: Hartsinck's werk van 1770, dat van Van Sypesteyn (niet Van Sijpesteyn), die aan het tijdvak in kwestie niet meer dan een halve pagina wijdde, alsmede twee werken van Teenstra, welke niets van eenig belang bevatten aangaande het Britsche bestuur, is mij niet duidelijk.

De Baron Albert von Sack (niet Van Sack en niet A. C. von Sack) wordt door E. genoemd in verband met zijn eerste bezoek aan Suriname en als de schrijver van een werk van 1821, geschreven na zijn tweede verblijf aldaar; of liever, van de Nederlandsche vertaling van dit werk wordt melding gemaakt. Heeft de auteur van de Narrative van 1810 niets medegedeeld betreffende zijn Surinaamsche ervaringen van 1805, 1806 en 1807, dat de moeite der vermelding waard was?

Wolbers heeft gebruik kunnen maken van de gegevens in het Algemeen Rijksarchief te 's Gravenhage en in „Her Majesty's „State papers office" te Londen; ook Einaar heeft de Haagsche en de Londensche archieven doorzocht en dat de resultaten van dit tweede onderzoek ons niet wijzer maken, dan wij reeds waren, bewijst dat het eerste met zorg was uitgevoerd.

De Britsche regeering wilde de Nederlandsche Westindische koloniën slechts stevig vasthouden, tot tijd en wijle de oorlog voorbij zou zijn en uitgemaakt zou worden, wat men wel en wat men niet zou kunnen en willen behouden; intusschen moesten die koloniën commercieel zooveel mogelijk aan de Engelsche belangen dienstbaar gemaakt worden, maar in de inwendige aangelegenheden mocht alleen in geval van noodzaak ingegrepen worden, dit laatste vooral opdat Engeland, bij eventueele teruggave, niet met allerlei klachten en vorderingen lastig gevallen zou worden.

In Suriname nam de bevolking de verandering van vlag nogal koeltjes op; ontevredenheid uitte zich pas toen het, onder Bonham, urgent geacht werd, tegen een der ernstigste Surinaamsche misstanden op te treden.

Van de Britsche gouverneurs was Bentinck de zwakste, Bonham de energiekste; eerstgenoemde heeft zich bemind gemaakt, maar de bestaande verwarring nog vergroot, laatstgenoemde heeft zich tegen een Cabale te weer moeten stellen, maar kon de voldoening smaken van het hem toevertrouwde pand in beteren staat dan waarin hij het gevonden had, aan de vroegere eigenaars te kunnen overdragen. 
Dit zijn in het kort de conclusies waartoe men komt wanneer men Wolbers gelezen heeft en Einaar's beschouwingen leiden niet tot andere.

Wat E. in de eerste alinea van zijn inleiding zegt over de periode 1802-1804, bevat blijkbaar een drukfout, waardoor er slechts naar geraden kan worden wat hij bedoeld heeft.

Deze dissertatie maakt (blz. 134) o.a. de verhoudingen in het Britsche staatsbestel niet heelemaal duidelijk. In 1794 werd een nieuwe Secretary of State for War tevens nominaal Secretary of State for the Colonies en in 1801 werd de vereeniging der beide departementen geregeld. Deze toestand bleef bestaan tot 1854, toen een vierde staatssecretaris benoemd werd, alleen voor Koloniën (in 1858 een vijfde voor Indië).

De staatssecretarissen voor Oorlog en Koloniën, gedurende den tijd dat Suriname onder Britsch bewind stond, waren: Robert, Lord Hobart (1801-1804), Earl Camden (1804-1805), Viscount Castlereagh (1805-1806), William Windham (1806-1807), niet Lord Windham (hij weigerde een Peerage, om in het Lagerhuis te kunnen blijven), Viscount Castlereagh (1807-1809), Robert Jenkinson, Earl of Liverpool (1809-1812), door Einaar wel als Lord Liverpool genoemd, maar niet in den index opgenomen, Henry, Earl Bathurst (1812-1827), door E. in den index Lord W. Bathurst genoemd.

Sir Edward Cooke (niet Sir Cooke) was in de eerste periode Castlereagh Under Secretary of State ${ }^{1}$ ).

Dat Engeland in het weinig begeerlijke Suriname geen staatsgeld wilde steken, is zeer begrijpelijk; van de groote voordeelen echter, welke tijdens het tusschenbestuur aan de Britsche schatkist toegevallen zouden zijn, is niets gebleken. Engeland onderhield in Suriname een sterke militaire bezetting (meestal twee regimenten, volgens Wolbers) en de opbrengst der inkomende en uitgaande rechten was ook vroeger niet aan de Kolonie ten goede gekomen, maar aan de Societeit.

Wat betreft de pogingen van Engeland om $Z$ weden met een der veroverde Nederlandsche koloniën tevreden te stellen, is het niet duidelijk wat er voor merkwaardigs in gelegen was (Einaar blz. 135), dat de Zweedsche Koning, wanneer hij Guadeloupe

1) Zie o.a.: Hugh Edw. Egerton, A short history of British Colonial Policy, 1609-1909, ninth edition, London 1932 en Dictionary of National Biography. 
niet krijgen kon, aan Berbice, Demerary en Essequibo tezamen de voorkeur gaf boven Suriname. Hoe het verder met dezen koehandel gegaan is, vertelt Van der Kemp ${ }^{1}$ ).

Het door E. geciteerde voorstel van Bonham, om den eenen of anderen vriend van het Oranjehuis en van het oude regiem te begiftigen met den niet onvoordeeligen post van eerste fiscaal in Suriname, bewijst hoe de gedachten der Engelschen steeds uitgingen naar het oude Holland der stadhouders, dat zoo lang hun bondgenoot geweest was.

De eigengereide, vrijgevochten koloniale samenlevingen, zooals die zich in de West gevormd hadden, onder Nederlandsche vlag, maar onder de leiding van particuliere maatschappijen, waren niet bepaald kweekplaatsen van nationale gevoelens; de blanke inwoners waren van verschillende landaarden en idieele beweegredenen hadden in het kolonisatieproces geen rol gespeeld. Van patriotisme kon onder deze omstandigheden nauwelijks sprake zijn, hoogstens van meerdere of mindere trouw aan een regiem.

Juriaen François Friderici, zoon van een Duitsch militair in Nederlandschen dienst en van een Kaapsch-Hollandsche boerendochter, was Oranjegezind; hij bleef Suriname besturen tijdens het Britsche protectoraat en zou dat gaarne wederom gedaan hebben toen de Kolonie opnieuw onder Engelsche (feitelijk vijandelijke) vlag kwam.

Politieke gezindheid beheerschte meer de gevoelens der kolonisten ten aanzien van de verandering van vlag, dan nationale en waarschijnlijk in nog sterkere mate werden die gevoelens beinvloed door de vraag, of men al dan niet van het Britsche bewind in materieel opzicht iets te hopen had.

„Buitengewone daden van heldenmoed en burgertrouw” bij den overgang van 1804 heeft Wolbers niet te vermelden gevonden; de meeste militairen van het garnizoen traden in Britschen dienst, rapporteerde Berranger.

Green nam begin Mei voorloopig het bestuur over Suriname op zich; reeds op 28 Juni d.a.v. haastte het Hof van Policie zich, om hem een extra jaarlijksche toelage uit de koloniale kas aan te bieden. Een „schitterende” waardeering van Green's „werk” noemt Einaar dit! Tevoren had men reeds aan de Britsche officieren een geldelijk douceur toegekend en, wat Wolbers wel, maar

1) P. H. v. d. Kemp, Teruggave der Oost-Indische Koloniën, 1910. 
Einaar niet vermeldt, men legde in 1806 zelfs aan den generaalmajoor Archer een groot jaargeld toe.

Pas toen onder Bonham krachtige maatregelen werden genomen ter bescherming der belangen van afwezige, Hollandsche, crediteuren, ontstonden wrijving en verzet. Onder de tegenstanders van den laatsten Britschen gouverneur waren die met Engelsche namen niet de minst roerige.

Alle vier de Koninklijke gouverneurs waren militairen, dus menschen die gewend waren zoowel om te gehoorzamen als om te bevelen en van nature minder geneigd dan de vroegere $\mathrm{Ne}$ derlandsche gezagdragers, om aan chicanerieën toe te geven, of zich te laten beinvloeden door de belanghebbenden ter plaatse.

Kan Bentinck om politieke redenen benoemd zijn, de drie anderen waren eenvoudig verdienstelijke, maar niet uitblinkende hoofdofficieren. Voor menschen als Hood, Beckwith c.s. had Engeland in den strijd op leven en dood, waarin het gewikkeld was, belangrijker werk te doen.

Dat Bentinck, die steeds nalatig was in zijn correspondentie met de Londensche autoriteiten, die gelden uit de Koninklijke kas toezegde voor den bouw eener Nederlandsch-Hervormde kerk te Paramaribo, terwijl de Engelsche inwoners alle geestelijke verzorging ontbeerden en, ten slotte, die medewerking verleende tot een allerbedenkelijkste regeling betreffende de bekostiging der interne verdediging, in Engeland geen vertrouwen genoot, ligt wel zeer voor de hand. Evenzeer, dat Bonham, wat betreft den financieelen toestand der Kolonie, voor een nog moeilijker taak kwam te staan, dan zijn voorgangers zich opgelegd gezien hadden.

Waardoor heeft Bonham getoond, alleen oog te hebben voor de Britsche belangen in engeren zin? Bij zijn plan, om aan de benadeeling der afwezige crediteuren paal en perk te stellen, waren toch niet in de eerste plaats deze belangen betrokken en het denkbeeld van een curator is hem blijkbaar door anderen aan de hand gedaan. In welken geest de Engelsche regeering tot de uitvoering der door haar goedgekeurde maatregelen medewerkte, blijkt mede uit de benoeming der beide commissarissen in Engeland, de in 1804 tot Engelschman genaturaliseerde Mr. Hendrik Fagel - de groote vriend der Oranjes, leermeester van den Erfprins - en de als auteur bekende Granville Penn, destijds waarschijnlijk nog assistant clerk in het War Department ${ }^{1}$ ). Deze

$\left.{ }^{1}\right)$ Nieuw Ned. Biogr. Woordenboek en Dictionary of Nat. Biogr 
beide Heeren steunden Bonham's beleid bij de regeering, zelfs toen er klachten kwamen van Engelsche kooplieden, zooals Wolbers mededeelt.

Dat Bonham bij zijn aftreden kon wijzen op een hersteld evenwicht tusschen inkomsten en uitgaven en op een tot $f$ 25.per $€$ gedaalden wisselkoers, lezen wij bij $\mathrm{E}$. niet; Van Wieringen wordt door den schrijver niet aangehaald ${ }^{1}$ ). Ook laat hij onvermeld het staaltje van Bonham's integriteit, dat Wolbers geeft; het geval der in de souvereiniteitskas berustende, maar niet aan den Koning toekomende $87^{1} / 2$ mille, uit de dagen der Societeit.

Het is waar, dat ten slotte de regeering niet met Bonham meeging in zake de recalcitrante curatoren der Boedelkamer. De betreffende brief van Bathurst echter was gedagteekend 25 Mei 1814 , nadat Napoleon op 6 April geabdiceerd had en op 20 April naar Elba vertrokken was; de teruggave van Suriname aan Nederland stond voor de deur, de Engelsche maatregelen ten bate der Hollandsche crediteuren konden gevoegelijk vervallen en het had geen zin de uit die maatregelen voortgevloeide rancunes te laten voortbestaan.

Over sommige politieke en militaire aangelegenheden had Einaar ons wel iets uitvoeriger kunnen inlichten.

Friderici, de Oranjeman, werd in 1795 door de Provisioneele Representanten van het Volk van Holland geprezen; hij werd echter in 1802 door het Staatsbewind niet opnieuw benoemd, maar zijn gewezen secretaris Pierre Berranger werd aangesteld. Deze laatste voorzag in 1804 blijkbaar dat het tweede Britsche bewind niet van langen duur zou zijn en wilde het met de Engelsche bevelhebbers op een accoordje gooien, iets waar Green en Hood (Einaar noemt hen in omgekeerde volgorde, maar de commandant der landmacht was hiërarchisch de eerste persoon) natuurlijk niet in konden treden.

Het Nieuw Nederl. Biogr. Woordenboek spreekt van den dapperen luitenant-kolonel Imbyse van Batenburg, Einaar van den luitenant-kolonel B. Batenburg, maar redresseert de naamsverwisseling in eerstgenoemde bron niet. Bloys van Treslong werd op 18 Juli $1806^{2}$ ) van al het hem in zake de overgave van Suriname ten laste gelegde vrijgesproken. Misschien was er in de ar-

1) A. G. van Wieringen, Geschiedenis der belastingen in de Kolonie Suriname, 1912.

2) Nieuw Nederl. Biogr. Woordenb. 
chieven nog wel iets vermeldenswaardigs aangaande dit proces te vinden geweest.

Wie was eigenlijk de „verrader” Hoop, of Van der Hoop, in 1804 ? Einaar noemt hem een Nederlander, Wolbers een Surinamer, Green schreef Mr. Van der Hoop from Surinam. Is S. C. P. van der Hoop, genoemd in de vergadering van den Raad van Marine van 18 Januari 1804, dezelfde als F. S. C. P. van der Hoop, die benoemd werd, door Bentinck, tot ontvanger der - Cassa tegen de Wegloopers?

De Britsche gouverneurs hadden als zoodanig te maken met de staatssecretarissen voor Oorlog en Koloniën, maar als militairen bovendien hiërarchisch met de Commanders in Chief of the Leeward Islands; de troepen in Suriname waren ten slotte ter beschikking van laatstgenoemde opperbevelhebbers. Dat uit deze dualiteit moeilijkheden ontstonden, is niet gebleken. Hoe het kon gebeuren dat Archer met ongegronde verwachtingen naar Suriname kwam, maakt Wolbers ons voldoende duidelijk.

E. geeft een meening betreffende de vermoedelijke oorzaken der muiterij van de zwarte Jagers in 1805. Is deze meening gebaseerd op den brief van Lord Castlereagh aan den gouverneur Hughes van 21 November 1805, dan ware het misschien van belang geweest dien door Wolbers genoemden brief in extenso op te nemen; nog onder het beruchte contract van 1811 werden aan deze landsverdedigers, volgens Bonham, provisiën van inferieure hoedanigheid verstrekt. Ook ware het allicht nuttig geweest, het rapport van den luitenant Green aan den gouverneur van 9 November 1808, nopens de verdediging van post $\mathrm{Ar}-$ mina (zie Wolbers), te publiceeren.

Wat den slavenhandel betreft, vindt E. het vreemd dat Wolbers de parlementsacte van 23 Mei 1806 citeert, waarbij de invoer gerantsoeneerd werd, in verhouding tot het aantal in iedere kolonie reeds aanwezige slaven, terwijl reeds 15 Augustus 1805 alle invoer, tenzij krachtens speciale vergunning, verboden was geworden. Waarom niet onderzocht of hier niet van wezenlijk verschillende regelingen sprake was? Men leefde immers in den tijd van "ineffectual efforts to tinker with the slave trade" ${ }^{1}$ ). Terwijl Wolbers vermeldt dat Gouverneur Hughes voor 1807 een invoer van 467 slaven in Suriname toestond, zegt E. dat er dat jaar 467 ingevoerd werden (zie aangaande de ingevoerde slaven verderop).

1) Egerton, Br. Colonial Policy, als voren. 
Zijn slechten naam met betrekking tot de behandeling der slaven kon Suriname wijten aan het ontbreken van een krachtig en onafhankelijk bestuur in den tijd der Societeit (E. noemt op bldz. 111 ook de West-Indische Company, maar deze heeft Suriname eigenlijk nooit bestuurd), aan het absentisme der plantage-eigenaars en, volgens Ds. Bosch ${ }^{1}$ ), aan het Duitsche plantagepersoneel.

Hoewel de Engelschen, van wie een aantal gruwelverhalen afkomstig is, vaak bevooroordeeld waren ten opzichte van de Hollanders, mag op deugdelijke gronden worden aangenomen dat, onder het $18 \mathrm{e}$ eeuwsche regiem, de ongunstige en de ongure elementen onder de blanke meesters lang niet voldoende in toom gehouden werden en dat de justitie niet onpartijdig en onbevangen was. En die 18e eeuw was tijdens het Engelsche bewind ook in Suriname nog lang niet voorbij.

Dat de zeer begrijpelijke afkeer der Engelschen van de wreede Surinaamsche strafoefeningen niet alleen uit zachtmoedigheid voortsproot, mag veilig aangenomen worden. $\mathrm{Zij}$ waren buitenstaanders en ergerden zich aan de wijze waarop met weerlooze delinquenten omgesprongen werd, die immers hun niets misdaan hadden; ook vrees had in Suriname tot wreedheid geleid en de vreemde militairen, die deel uitmaakten van een aanzienlijke legermacht, bestemd om in een internationaal conflict voor hun land te strijden, konden gemakkelijk de oogen sluiten voor het gevaar welke die „poor wretches" van slaven onder bepaalde omstandigheden konden opleveren.

Was hun eigen gramschap opgewekt, meenden zij dat het gezag aangerand was, of de veiligheid bedreigd werd, dan gedroegen de Engelschen zelf zich nooit bijzonder teerhartig; daarvan getuigen de ranselpartijen in de $18 \mathrm{e}$ eeuw bij marine en leger, de berechting der Indische muiterijen van 1806 en 1857, het optreden tegen de Matabelen in 1893 enz.

Niet alle Britsche militairen waren principieele tegenstanders der slavernij; van Fred. Maitland, die als brigade-generaal aan de verovering van Suriname in 1804 deelnam en later luitenant-gouverneur van Grenada was, vinden wij aangeteekend dat hij anti-abolitionist was ${ }^{2}$ ). Ook geven de bewoordingen der door Wolbers overgenomen proclamatie van 11 Juli 1804, betreffende de manumissie, niet bepaald blijk van een innige overtuiging

1) G. B. Bosch, Reizen in West-Indië, I, 1829.

2) Dict. of Nat. Biogr. 
bij Gouverneur Green, ter zake van het natuurlijke recht van ieder mensch op lichamelijke vrijheid.

Dat het Britsche gouvernement, ten aanzien van de weerzinwekkende strafoefeningen in het fort Zeelandia, in een lastig parket verkeerde, is begrijpelijk. De Bataafsche Republiek had, naar Fransch voorbeeld, de pijnbank afgeschaft en het Engeland van destijds kende haar niet. Deze instelling echter diende om een verdachte tot bekentenis te brengen, of om een veroordeelde op afschrikwekkende wijze ter dood te brengen en in deze beteekenis was zelfs een Spaansche bok geen marteling. Dat de Surinaamsche autoriteiten zich beleedigd achtten door het verwijt "torture" toe te passen, of te dulden (brief Spiering aan Hughes), was dus niet zoo ongerijmd.

De persoonlijke gevoelens der Britsche gezagdragers behoefden ook in deze aangelegenheden geen overwegende rol te spelen; E. dicht hun veel te vaak zoodanige gevoelens, neigingen, opvattingen en motieven toe, waar de ambtelijke stukken slechts getuigen van een streven om de lijnen van algemeen beleid te volgen, door de moederlandsche regeering aangegeven, of van zelf uit de Engelsche politiek van dien tijd voortvloeiend. Dat Hughes het radbraken als een vorm van ter dood brengen voorloopig verbood en verder „His Majesty's pleasure” afwachtte, was een volkomen voor de hand liggende procedure.

Intusschen is er door de Britsche landvoogden zeker iets gedaan om aan de willekeur tegenover de slaven eenigermate paal en perk te stellen, onder den invloed natuurlijk der in Engeland steeds veldwinnende beweging, weldra een agitatie, tegen de slavernij, welke spoedig tot een zoo hevige confusie zou leiden ${ }^{1}$ ). Waarom echter vertelt $\mathrm{E}$. ons niet welke maatregelen Bonham eigenlijk invoerde (blz. 112)?

Een gunstig resultaat der Britsche interventie was ook, dat Nederland, bij de teruggave der koloniën, ingevolge de Londensche conventie van 1814, bekrachtigd door den vrede van Parijs van 1815 , zich verbond den slavenhandel met alle middelen tegen te gaan.

Het vreemde gezag echter heeft nog meer voor Suriname gedaan. Zooals wij reeds gezien hebben, heeft het in den financieelen toestand, welke volgens de bevindingen van het provisioneele bewind van 1802 erbarmelijk was, een belangrijke verbetering tot stand weten te brengen; in Bonham's tijd werd niet alleen

$\left.{ }^{1}\right)$ Egerton, Br. Colon. Policy, als voren. 
geen nieuw kaartengeld uitgegeven, maar er werd zelfs voor $f 150.000$ vernietigd.

De Surinaamsche Augiasstal was daarmede wel niet afdoend gereinigd, maar dat kunnen de Engelschen zich ook niet voorgenomen hebben. Hun eigen 18e eeuw was ook nog niet voorbij en zij heeft in sommige opzichten langer geduurd dan de onze; er was een Great Mutiny noodig om de East India Company als bestuursorgaan definitief te doen verdwijnen.

Nieuw voor Suriname was het instituut van een overzeesche vertegenwoordiging, door een agent te Londen, die van de Kolonie een matig salaris genoot. Ook nieuw was de invordering der inkomende en uitgaande rechten, buiten bemoeienis van het koloniale bestuur, rechtstreeks namens den Souverein, door het Custom House, dat vrijwel onafhankelijk van den gouverneur was, zooals uit het incident van 1808 bleek.

Dat in den Engelschen tijd de vendumeester elders gevestigd kon zijn en zich in Suriname door een „deputy" kon laten vertegenwoordigen, was een stukje verouderd koloniaal beleid, zonder weerga in de Hollandsche geschiedenis der Kolonie. De „patentee", Sir Walter James, is een onbekende grootheid, maar van zijn tweeden gedeputeerde, Henry Bolingbroke, die zes jaar in Suriname geweest is en ook in Demerary vertoefde, is een reisbeschrijving bekend, „A voyage to the Demerary" ${ }^{1}$ ).

Kwam Nederland na de Napoleontische oorlogen voor geheel nieuwe problemen te staan, o.a. de verhouding eener constitutioneele monarchie tegenover haar tropische koloniën, voor Engeland trad na den vrede de periode in, gedurende welke men zich zou gaan afvragen, waarvoor koloniën nog goed waren, wanneer men die niet meer exploiteeren kon ten bate van het moederland (slavenemancipatie en vrijhandelsgeest). De apathische bureaucratie, waartoe men met betrekking tot de koloniën verviel, werd door Chs. Buller in 1840 beschreven, of gepersifleerd, in zijn „Mr. Mothercountry of the Colonial Office” ${ }^{2}$ ) Met de geschiedenis van Suriname onder Britsch bestuur heeft dit niets meer te maken, maar E. heeft het in zijn slotbeschouwingen over Mr. Mothercountry.

Over de economische gevolgen, welke de Britsche annexatie voor Suriname gehad heeft, zegt E. niet veel; in zake het „Colonial Pact" neemt hij alleen zooveel van Prof. Egerton over, als

1) Dict. of Nat. Biography.

$\left.{ }^{2}\right)$ Overgenomen in Wakefield's View of the Art of Colonization. 
noodig is om te doen begrijpen waar het voor de koloniën op neerkwam, zonder er historische beschouwingen aan vast te knoopen.

Wat op blz. 37 te lezen valt, aangaande neutrale en vijandelijke schepen, is niet wel begrijpelijk. Op blz. 40 oppert E. de veronderstelling dat Green ,wellicht" de Surinaamsche suiker voor de Engelsche markt wilde bestemmen (sic). Hoe de toestand was, met betrekking tot de V. S., nadat de war of impressment uitgebroken was (blz. 100 en 106), is niet duidelijk.

Dat de Surinaamsche handelsbalans ongunstig was, willen wij gaarne op E.'s gezag gelooven, maar uit het feit, dat de invoer in tonnen grooter was dan de uitvoer in tonnen, behoeft het toch niet te volgen, zou men zoo zeggen. Tegenwoordig voert Suriname waarschijnlijk kwantitatief meer uit dan in, maar men mag zich toch wel eens afvragen, welke waarde de handelsbalans heeft (die in geldswaarden natuurlijk) voor een land, waar ongeveer al het uitgevoerde voor uitheemsche rekening geproduceerd is. Op blz. 136 spreekt E. over een uitvoerexcedent, niettegenstaande de pogingen om de handelsbalans gunstig te houden(!)

Wie van cijfers en andere feitelijke gegevens houdt, zal in E.'s dissertatie niet zooveel vinden als hij zou wenschen.

Green zond op 2 October 1804 aan Lord Camden een lijst der plantages, met de namen der eigenaars en die der vertegenwoordigers van de afwezige belanghebbenden. Waarom die lijst niet gepubliceerd?

Tot welk resultaat de pogingen om den waterweg tusschen de Surinamerivier en de Saramacca te verbeteren, geleid hebben, vernemen wij niet. Dat er in Hughes' tijd Fransche negers voor gehuurd moesten worden, geeft E. geen aanleiding tot commentaar.

Wolbers spreekt van een op 1 Januari 1808 opgemaakte lijst van ingevoerde slaven (in verband met de hiervoor behandelde invoerpermissies). Was het niet van belang deze lijst in haar geheel over te nemen?

Het bevolkingsstaatje van 31 Augustus 1805 komt ook bij Wolbers voor, alsmede in de Encyclopaedie voor Nederl. W.-I., maar dáár met de toevoeging dat boschnegers en Indianen er niet in begrepen zijn; of al dan niet met het garnizoen rekening gehouden is, blijkt uit geen der drie bronnen.

Volgens Wolbers moet er een overzicht bestaan van den stand der verschillende kassen, onder Bonham's bestuur door den 
boekhouder-generaal Andrew Melville opgemaakt. Was het niet goed geweest, dit overzicht te publiceeren?

Voor 1811 worden ons opnieuw bevolkingscijfers voorgezet; $\mathrm{E}$. komt tot 57041 inwoners, Wolbers, die dezelfde gegevens gebruikte, tot 55829, zonder de militairen, de Enc. v. Ned W. I. tot 59458 , zonder boschnegers en Indianen. De indeeling volgens de godsdienstige gezindten is bij E. anders dan bij Wolbers. Had aangaande deze materie niet aan alle onzekerheid en onduidelijkheid een eind gemaakt kunnen worden?

De lijst van al het papiergeld, dat in omloop was, is nieuw; zij is echter niet gedagteekend en wij hebben geen middel om na te gaan, op welk tijdstip die lijst betrekking heeft. E. teekent in een noot aan ,,deze opgave is onjuist" en inderdaad kan er een telfout van $f 54.000$ geconstateerd worden; er werd in dien tijd slordig gecopieerd.

Ten slotte de memories van Heshuysen.

Er was tot dusver één van gepubliceerd, die betreffende de Indianen $\left.{ }^{1}\right)$, geschreven tijdens het Britsche protectoraat van 17991802. De memories uit het tijdperk $1804-1816$ worden ook door Wolbers genoemd, die ze echter niet in extenso opneemt. Of E. nu compleet gepubliceerd heeft alles wat Heshuysen voor het tweede Britsche bewind opstelde? Vergelijking met de aanteekeningen van Wolbers doet er soms aan twijfelen. Eén verslag van Heshuysen zegt E. ons nog toe (blz. 74); jammer dat hij het niet direct overgenomen heeft.

Nieuwe biographische bijzonderheden aangaande den auteur van al die memories geeft $\mathrm{E}$. ons niet; hij laat het bij de vermelding van hetgeen Oudschans Dentz indertijd aangaande Heshuysen medegedeeld heeft ${ }^{2}$ ). Waarom spreekt E. voortdurend over F. van Heshuysen, of van Heshuysen? Voor zoover valt na te gaan heette de man Floris Visscher Heshuysen. Had hij gestudeerd?

Voor de kennis van menschen en toestanden ware het misschien nuttig geweest de memorie op te nemen welke de eerste fiscaal E. G. Veldwijk aan zijn verzoek om ontslag toevoegde. Zijn opvolger was S. M. Schuster, of M. S. Schuster; volgens Wolbers Mr. M. J. Schuster.

Om op de bron van inlichtingen terug te komen, welke de publicatie der verhandelingen van den boekhouder-generaal voor

1) West-Indische Gids, VII, 346.

2) West-Indische Gids, VII, 571 . 
ons opent, wanneer men die memories bijE. leest en tracht ze te begrijpen, krijgt men den indruk dat Heshuysen, in tegenstelling met hetgeen Bonham van hem getuigde, slecht Fransch schreef. Vermoedelijk echter heeft E. slechts copieën gebruikt, of zelf slordig gecopieerd; ook in de Engelsche citaten komen hier en daar onduidelijke passages voor, welke aan schrijf- of drukfouten doen denken.

E. zou een nuttig werk verricht hebben, door een nauwkeurige Nederlandsche bewerking der memories te geven, ingedeeld naar de zeer uiteenloopende onderwerpen, soms in dezelfde memorie behandeld (die aangaande den regeeringsvorm bevat van alles en nog wat) en dan liefst hier en daar geannoteerd; wanneer Heshuysen het heeft over de auteurs van het essai historique, dan bedoelt hij stellig David D. J. C. Nassy en de andere „geleerde „Joodsche mannen", maar dat weet niet iedereen.

Deze boekbespreking heeft een wel wat ongewone uitgebreidheid verkregen, maar, hoewel het door E. behandelde tijdperk misschien niet zoo heel belangrijk is, achtte ik het toch voor de kennis der geschiedenis van Suriname van eenig gewicht, dat deze dissertatie niet als het laatste woord beschouwd worde over het Engelsche tusschenbestuur van 1804-1816.

Een staaltje van mooi, of van ook maar goed verzorgd $\mathrm{Ne}-$ derlandsch, is dit proefschrift niet. Ik zal geen voorbeelden aanhalen en had over de taal wel heelemaal willen zwijgen, ware het niet dat de Heer Einaar een Surinamer is en dit in verband gebracht zou kunnen worden met de wijze waarop hij zich uitdrukt.

Behoorlijk onderwezen Surinamers echter hebben geen moeite met het Nederlandsch, dat even goed hun taal is als de onze. Wij hebben hier dus weder te maken met het bekende, algemeene en vaak besproken euvel, dat heden ten dage aan het gebruik der moedertaal te weinig zorg besteed wordt. Misschien is slordig Hollandsch nog wel erger in een dagblad dan in een academisch proefschrift.

Aangaande de formuleering van enkele der twaalf door den Heer Einaar verdedigde stellingen had ik gaarne iets in het midden gebracht, maar daarmede zou ik het bestek dezer bespreking al te veel te buiten zijn gegaan.

Amsterdam, Februari 1935. 